\title{
Why We Need a Generalized Darwinism, And Why Generalized Darwinism is Not Enough
}

\author{
Geoffrey M. Hodgson and Thorbjørn Knudsen \\ Published in Journal of Economic Behavior and Organization, September 2006
}

7 September 2005

The Business School, University of Hertfordshire, De Havilland Campus, Hatfield, Hertfordshire AL10 9AB, UK
and $\begin{gathered}\text { Department of Marketing, University of Southern Denmark, Odense Campus, } 5230 \text { Odense M, Denmark } \\ \text { Address for correspondence: } \\ \text { Malting House, } 1 \text { Burton End, West Wickham, Cambridgeshire CB1 6SD, UK } \\ \text { g.m.hodgson@herts.ac.uk }\end{gathered}$

KEY WORDS: evolution, Darwinism, complex systems, self-organization, intentionality

JEL classification: B52, D83, O10, O30

\begin{abstract}
Complex evolving systems, consisting of populations of varied and replicating entities are found in both nature and human society. There exists no alternative to the core Darwinian principles of variation, selection and inheritance to explain the evolution of such systems. Neither the actual existence of human intentionality nor the hypothetical possibility of Lamarckian acquired character inheritance offers a barrier to the use of Darwinian principles. On the contrary, Darwinism is always required to complete the explanation. However, while Darwinian principles are always necessary to explain complex evolving population systems they are never sufficient on their own.
\end{abstract}




\section{Why We Need a Generalized Darwinism, And Why Generalized Darwinism is Not Enough}

What is 'evolution'?1 At least on etymological or historical grounds, there is little point in trying to give the word a narrow or well-defined meaning. Etymologically, like the word 'development', 'evolution' derives from the Latin verb volvere. This means 'to roll' but it can refer more broadly to the general idea of motion. The companion verbs evolvere and revolvere are more explicit, respectively denoting forward and backward motion, as in the unrolling and rolling-up of a scroll. The word 'evolution' therefore derives from the Latin word associated with a specifically directional and predestined activity; the scroll is unrolled to reveal that which is already written within. In this spirit the word 'evolution' was first applied to natural phenomena by the German biologist, Albrecht von Haller, in 1744. He used the word to characterize embryological development as the augmentation and expansion of a preformed miniature adult organism, a common idea in the seventeenth and eighteenth centuries. Indeed, in biology, the idea of preformation, where the embryo is deemed to contain in microcosm the form of its future development, lasted well into the nineteenth century, being embraced explicitly by Herbert Spencer and subtly affecting Charles Darwin's thought (Richards 1992).

Spencer did much more than Darwin to popularize the term 'evolution'. In the first edition of the Origin of Species, Darwin did not use this word and only once wrote 'evolved'. Subsequently he infrequently used the term 'evolution,' but on the whole he preferred phrases like 'descent with modification'. Today 'evolution' is used in a number of senses, and there is little basis to claim that any one has greater legitimacy. Accordingly, no Darwinian copyright can be imposed on the word 'evolution'. Furthermore, attempts to define evolution in some narrower and sharper sense, whether Darwinian or otherwise, are unlikely to make much headway.

Instead of starting from the vague and fruitlessly contested word 'evolution', we prefer to commence from the types of phenomena involved. We refer to a broad class of systems and populations of entities, including all feasible manifestations of development and change. We then show, under some minimal conditions, that ongoing change in such systems is inevitably Darwinian in the sense that it must involve Darwin's central principles of variation, inheritance and selection.

It is demonstrated that this central argument can resist a number of objections. For instance, some authors point to the theory of self-organization and suggest that it is an alternative to Darwinian selection. Others point to human intentionality and claim that it is inconsistent with

\footnotetext{
1 The authors are very grateful to Guido Bünstorf, Christian Cordes, Peter Corning, James F. Crow, Ian Gough, David Hull, Joel Mokyr, Richard Nelson, Peter Richerson, Viktor Vanberg, Jack Vromen, Richard Webb, Ulrich Witt, anonymous referees and many others for inspiration, discussions and critical comments. This essay makes use of some material from Hodgson (2002).
} 
the 'blind' processes of Darwinism. Others regard Lamarckism and Darwinism as rivals, seeing social evolution as an exemplification of the former rather than the latter.

We shall argue that all these objections are mistaken in crucial respects. Processes of selforganization are important in nature and society. Human intentionality and choice are distinctive and should not be ignored. It is proposed by many that the Lamarckian inheritance of acquired characters may occur in social evolution. But none of these propositions rules out Darwinism. On the contrary, all accounts require Darwinian principles to complete their explanations.

We acknowledge fully that the detailed mechanisms of change are often very different, both within and between different types of system, in nature and in human society, but again, as argued below, this does not undermine a generalized Darwinian analysis. ${ }^{2}$

Much progress in broadly-defined 'evolutionary' thinking in the last three hundred years has involved the development of the insight that complex outcomes are not necessarily the result of deliberate design, by humans or by God. Such a theme is found in the writings of Bernard Mandeville, David Hume, Adam Smith and Carl Menger, as Friedrich Hayek (1973, 1988) and others have discussed extensively. All these writers pointed to the emergence of undesigned social orders and institutions that resulted from individual interactions.

This was a highly significant but incomplete step. Writers such as Mandeville and Smith did not explain how the individuals and their dispositions had themselves evolved, and they gave only limited insights into why particular undesigned outcomes would survive longer than others and could thereby be copied or imitated. Darwin (1859) filled these gaps with his principle of selection. Humans who were more adapted to their environment would have a survival advantage over others.

In contrast to the view that Darwinism is domain-specific, Darwin (1859, pp. 422-3; 1871, vol. 1, pp. 59-61, 106, 166) himself proposed that natural selection operates upon the elements of language and argued that tribal groups with moral and other propensities that served the common good would be favored by natural selection. Following this lead, other writers such as Walter Bagehot (1872), David Ritchie (1896) and Thorstein Veblen (1899) argued that the principle of selection could help explain the survival not only of individuals, but also of groups, customs, nations, business firms and other social institutions. ${ }^{3}$

While Mandeville, Hume, Smith and Menger had shown how undesigned social orders and institutions can emerge, the Darwinian social theorists showed how some but not all of them might survive, without presuming that their adaptedness ${ }^{4}$ was already explained. The principle

\footnotetext{
2 The idea of a generalized Darwinism was described by Dawkins (1983) and others subsequently as 'Universal Darwinism'. We have no strong objection to this term, but it should be pointed out that the idea of applying Darwinism to the evolution of social entities pre-dates Dawkins's essay by more than a century. Generalizing Darwinism does not itself imply any adherence to Dawkins's other views.
}

\footnotetext{
3 See Hodgson (2004) for a discussion of these and other early attempts to extend Darwinism to social evolution. Note that we generally use the term 'social' in a broad sense, to include business and other phenomena studied by economists. After a long period of neglect, today Darwinian ideas are widely discussed in economics and organizational sociology. In this essay we cite a number of leading evolutionary economists.

${ }^{4}$ Following a convention suggested in biology, adaptedness refers to the fitness value of a trait or trait-complex in a specific environment with respect to the current circumstances. By contrast, adaptation denotes the process
} 
of selection provides the means of explaining adaptedness and survival, without assuming that the capacities to adapt and survive are given or decreed by a divine Creator.

This paper is divided into six further sections. Section one describes the broad type of 'evolutionary' system that we are required to explain and shows why Darwinian principles are unavoidable in dealing with such systems. Section two argues that self-organization theory is insufficient to explain the evolution of the complex systems discussed here and itself requires Darwinism to complete its explanations in such a context. Section three acknowledges that human intentionality is distinctive and important, but shows that it does not limit or exclude Darwinism. Section Four deals briefly with the issue of 'Lamarckism' and shows that even if acquired character inheritance did occur in the natural or the social world; it would not provide a complete evolutionary explanation. Darwinism would still be required. Section five gives the other side of the coin; while Darwinian principles are always necessary to explain complex evolving population systems, they are never sufficient on their own. Attention to specific, detailed mechanisms is always required. Section six concludes the essay.

\section{Complex population systems and the inevitability of Darwinism}

What kind of systems are we required to explain? Rather than simple, mechanical systems, the objects or our discussion are complex systems, at least in the sense that they involve a variety of entities that interact with one another. Such complex systems produce some outcomes that are not willed by any individual entity and have properties that do not correspond to any individual entity taken alone.

Still retaining a high degree of generality, we may add some further details to this picture. The complex systems considered here involve populations of entities of specific types. Members of each type are similar in key respects, but within each type there is some degree of variation, due to genesis, circumstances or both.

Entities within these populations have limited capacities to absorb some materials and energy from a sector of their environment in some manner of consumption, and they are able to process some information about their environment attained by the use of some sensory mechanisms. Beyond that, we do not need yet to go into further detail about their cognitive and informational capacities. These entities may or may not have a developed brain or memory. They may or may not be capable of reflecting on their circumstances and imagining past or future behaviors.

Some further elements are necessary to complete the picture. All these entities are mortal and degradable, and they need to consume materials and energy in order to survive or minimize degradation. However, because they do not have access to all environmental resources at once, these entities face an omnipresent problem of local and immediate scarcity. ${ }^{5}$ These circumstances present specific problems that have to be solved to minimize

\footnotetext{
of becoming adapted in terms of an evolutionary history. Thus, in its present use, adaptedness refers to the features of organisms; adaptation (as a verb) refers to the process of becoming adapted. A second meaning of adaptation (as a noun) is a phenotypic adjustment to a characteristic in the environment. This use is commonly employed in economics and organization theory but not in biology. We shall use the term both as a verb and as a noun, in these respective senses.
}

5 The concept of scarcity is widely assumed by economists but rarely defined or discussed in detail. When Robbins (1932) regarded economics as the science of choice under scarcity, he defined scarcity loosely as a resource that is 'limited'. But there is a big difference between global or absolute scarcity and scarcity in a local 
degradation and raise the chances of survival. In short, these entities are engaged in a struggle for existence, to use the term adopted by Darwin (1859, pp. 62-63).

Finally, we assume some capacity to retain and pass on to others workable solutions to problems faced in the struggle for existence. The advantages of retaining such problem solutions or adaptations are obvious in avoiding the risks and labor of learning them anew. Given that all these entities are mortal and degradable, there are also good reasons to assume that some capacity to pass on to others information about such workable solutions exists. ${ }^{6}$

This is the basis of the Darwinian principle of inheritance. It refers to a broad class of mechanisms, including those of 'replication' and 'descent' (Mayr 1991), by which information concerning adaptations is retained, preserved, passed on or copied through time.

In sum, a complex population system involves populations of non-identical (intentional or non-intentional) entities that face locally scarce resources and problems of survival. Some adaptive solutions to such problems are retained through time and may be passed to other entities. Examples of populations in such systems are plentiful both in nature and in human society. They include every biological species, from amoebas to humans. They would include self-replicating automata, of the type discussed by John von Neumann (1966). In addition, and importantly for the social scientist, they include human institutions, as long as institutions may be regarded as cohesive entities having some capacity for the retention and replication of problem solutions. Such institutions would include business firms. ${ }^{7}$

Having sketched in broad terms the type of 'evolutionary' system we are considering, we now come to the crucial step in the argument: an adequate explanation of the evolution of such a system must involve the three Darwinian principles of variation, inheritance and selection. ${ }^{8}$ These are the broad Darwinian theoretical requirements. They do not themselves

and immediate sense. Many global resources are limited. However, other global and useful resources such as skill, trust and honor do not face the same physical constraints. The problem of scarcity is ubiquitous only with regard to some immediately available resources, and even then there are cases where some local resources can be in abundance.

6 An adequate explanation of why information retention and replication exist in such a system would invoke Darwinian selection between species that varied in such capacities. Our first step here is to assume a likely type of complex population system rather than to explain it. It will be clear from the examples below that the type of complex population system that we are assuming is highly relevant for evolutionary discourse in the social sciences.

7 Others may prefer to describe replicating social entities more broadly as 'memes' (Dawkins 1976). But the choice of label does not affect our general argument here. On the origin and significance of the idea of institutions as repositories of information see Hodgson (2004). Note also the related treatments of firms and routines by Nelson and Winter (1982) and Hodgson and Knudsen (2004).

${ }^{8}$ We fully acknowledge that the prominent conceptions of Darwinism, and how Darwinians have presented its message, have themselves evolved to some significant degree since 1859. Recently, for example, there has been acknowledgement of evolution on multiple levels and of complex interdependencies that undermine some previous (gene-centered) attempts at explanatory reduction (Hull 1985, Depew and Weber 1995, Keller 2002). Nevertheless, the three core principles of variation, inheritance and selection have endured. They are prominent in the long, final paragraph of the Origin (Darwin 1859). These core principles long pre-dated and existed independently of the 1940s synthesis of Darwinism with Mendelian genetics and the discovery of the structure of DNA in 1953. A generalized Darwinism essentially invokes the three core principles, not these auxiliary developments. 
provide all the necessary details, but nevertheless they must be honored. Otherwise the explanation of the evolution will be inadequate.

Consider the three Darwinian principles in turn. First, there must be some explanation of how variety occurs and how it is replenished in a population. In biological systems the answers here, established since Darwin's death, involve genetic recombination and also rare mutations. There are no closely analogous mechanisms in the evolution of social institutions, but the existence and replenishment of variety remains a vital question of evolutionary research (Metcalfe 1998, Nelson 1991, Saviotti 1996).

Second, there must be an explanation of how useful information concerning solutions to particular adaptive problems is retained and passed on. This requirement follows directly from our assumptions concerning the broad nature of the complex population system that we are required to explain, in which there must be some mechanism by which adaptive solutions are copied or passed on. In biology these mechanisms often involve genes and DNA. In social evolution we may include the replication of habits, customs, rules and routines, all of which may carry solutions to adaptive problems. ${ }^{9}$ There must be some mechanism that ensures that some such solutions (embodied in habits, routines or whatever) endure and replicate; otherwise the continuing retention of useful knowledge would not be possible.

Third, and not least, there must be an explanation of the fact that entities differ in their longevity and fecundity. In given contexts, some entities are more adapted than others, some survive longer than others, and some are more successful in producing offspring or copies of themselves. Here the principle of selection comes in. Briefly, selection involves an anterior set of entities, each interacting with its environment and somehow being transformed into a posterior set where all members of the posterior set are sufficiently similar to some members of the anterior set, and where the resulting frequencies of posterior entities depend upon their properties in the environmental context. ${ }^{10}$ Through selection, a set of entities, a population, will gradually adapt in response to the criteria defined by an environmental factor. In a cold environment, the proportion of mammals with more fat or longer fur is likely to increase.

This broad definition of selection is nevertheless sharp enough to distinguish itself from the principle of variation. The latter requires some explanation of the sources and replenishments of variety. Selection refers to the mechanisms that bring about the survival of some variations rather than others, often reducing variety. Even when both variety-creation and selection involve human agency, as often is the case in the human domain, the two processes are quite different. Innovation is about the creation of new variations; selection is about how they are tested in the real world.

Note that the outcomes of a selection process are necessarily neither moral nor just. Furthermore, there is no requirement that outcomes of a selection process are necessarily optimal or improvements on their precursors. Insofar as these outcomes carry connotations of refinement or efficiency, it is efficiency relative to the given environment, and efficiency that is tolerable rather than optimal. Darwinism does not assume that selection brings about globally efficient or (near) optimal outcomes, and in certain instances selection can even lead

9 See for example, Veblen (1899, 1919), Keller (1915), Nelson and Winter (1982), Hayek (1988), Hodgson (2003).

10 The technical definition of selection is explored at greater length elsewhere (Price 1995, Knudsen 2002, 2004). 
to systematic errors (Hodgson 1993, Hull 2001). There is no reason to believe that the special requirements needed to asymptote global efficiency are commonly present in nature or society (Gould 2002, Winter 1971).

Without the principle of selection, we have no way of explaining how some entities or their offspring prevail over others. The principle is widely held to apply in the natural world; the fitter members of the species often have greater chances of survival and procreation. This helps to explain how species become adapted to their environment. But the move from the natural to the social world does not undermine the principle of selection. Even if there is not a fierce life-and-death struggle between rival customs or institutions, some explanation is required of why some enjoy greater longevity than others, why some are imitated more than others, and why some diminish and decline. Any such explanation must come under the general rubric of selection, as defined above.

Darwin's principles of variation, inheritance and selection are required not only to explain evolution within populations but also the origins of those populations themselves. Together, the three principles provide a framework for understanding speciation as well as other forms of evolution.

Overall, as long as there is a population with imperfect inheritance of their characteristics, not all of them having the same potential to survive, then Darwinian evolution will occur. The following sections deal with a number of objections to the proposition.

\section{The insufficiency of self-organization theory}

The existence of self-organized, complex outcomes shows that we do not always have to look for a designer to explain their emergence. This insight is important in the social sciences because it counters the view that all social phenomena are the result of conscious design. Many complex and efficacious human institutions such as language and common law are not the outcome of an overall plan.

Self-organization is also very important in nature. We can observe intricate patterns and complex outcomes that are the result of interactions and accumulated steps. Just as selforganization reminds us that not every human creation is the result of a plan, it also removes the hand of God from explanations of many wonders of nature. But is self-organization sufficient to explain the origin of species and all complex biological phenomena? The definite answer is no. Darwin's principle of selection is also required.

Unfortunately, some writers, marveling at the outcomes of self-organization, have proposed that it is sufficient as an evolutionary explanation of all complex phenomena. In both biology and the social sciences they have thus downplayed the importance of evolutionary selection and the importance of the Darwinian intellectual revolution. Although he embraced much of Darwinism, Hayek (1973, pp. 22-23) belittled its significance with the statement: 'Those eighteenth-century moral philosophers and the historical schools of law and language might well be described ... as Darwinians before Darwin. ... A nineteenth-century social theorist who needed Darwin to teach him the idea of evolution was not worth his salt.' This underestimates the importance of the specific contribution of Darwin, especially in terms of 
the principle of selection, and encourages others to place more emphasis on the emergence of undesigned social order than on the sifting and selection of rival social institutions. ${ }^{11}$

Similarly, John Foster (1997) proposes that the theory of self-organization provides a sufficient, general basis for evolutionary thinking in economics, and Ulrich Witt (1997, p. 489) argues that the 'theory of self-organization ... provides an abstract, general description of evolutionary processes.'

In response, we first consider the role of self-organization in living systems. Close examination of their writings shows that leading proponents of self-organization in biology do not see it as an alternative to natural selection.

At a very fundamental level, the self-organization of chemical hypercycles is thought to explain the emergence of life. Emergent chemical hypercycles provide the feedback necessary for the emergence of self-reproducing metabolic networks. In the absence of emergent hypercycles, there would be no positive feedback for growth, implying that metabolic networks would simply die out (Eigen and Schuster 1979, Hofbauer and Sigmund 1998, Kauffman 1993). Once self-reproducing metabolic networks have emerged, however, a selection process is required for these entities to continue to increase in complexity. This is one of the major findings in the hypercycle literature.

Stuart Kauffman (1993) made a powerful argument that natural selection alone cannot explain the origin of complex organisms. Systems involving non-linear interactions comprise a large number of possible states, most having little survival value. Kauffman argued that processes of self-organization channel systems into more restrictive possibilities by way of positive feedback. However, Kauffman (1993) further argued that selection sustains organisms of a level of complexity beyond that explained by the principles of selforganization in isolation.

In the absence of self-organization, there will be no emergence of self-reproducing organisms. In the absence of selection, however, there will be no move towards the emergence of increasingly complex structures. Thus, rather than being alternatives, Kauffman (1993, p. 465) saw a 'natural marriage of self-organization and selection'. He and several other pioneers of self-organization theory do not present their argument as an alternative to Darwinian theory. Jeffrey Wicken (1987) wrote of 'extending the Darwinian paradigm', not exterminating it. David Depew and Bruce Weber (1995) considered 'Darwinism evolving', not Darwinism abandoned. Weber and Depew (1996, p. 51) wrote:

the very concept of natural selection should be reconceived in terms that bring out its dynamical relationships with chance and self-organization. In our view, Kauffman's recent work, as expressed in The Origins of Order, does just this.

What is involved here is a revision and extension of natural selection theory, not its negation. Kauffman (1995, p. 8) himself called for a 'revision of the Darwinian worldview' not its abandonment. As Kauffman (1993, p. 644) also related:

11 Hayek (1973, p. 23) went on to hint at generalized evolutionary principles. He distinguished between 'the selection of individuals' and 'that of institutions and practices' and on 'the selection of innate rather than on culturally transmitted capacities of individuals.' He thus differentiated between the selection of biological and social entities and then proposed that 'the basic conception of evolution is still the same in both fields.' However, to complete the picture, he should have highlighted that (according to his own account) 'selection' is central to this 'basic conception of evolution', and then acknowledged that the principle of selection does not pre-date Darwin in the manner of his more broadly and loosely defined 'idea of evolution'. 
I have tried to take steps toward characterizing the interaction of selection and selforganization. ... Evolution is not just 'chance caught on the wing.' It is not just a tinkering of the ad hoc, of bricolage, of contraption. It is emergent order honored and honed by selection.

Kauffman's (2000) later work on self-organization reinforces this point. Once selforganized systems and subsystems emerge, natural selection acts upon these self-organized structures once they emerge. Far from being an alternative to natural selection, selforganization requires it in order to determine which self-organized units have survival value. Accordingly, other self-organization theorists, such as the biologists Scott Camazine and his colleagues, similarly recognize that self-organization complements rather than displaces the 'orthodoxy’ of natural selection. Echoing Kauffman, Camazine et al. (2001, p. 89) write,

There is no contradiction or competition between self-organization and natural selection. Instead, it is a cooperative 'marriage' in which self-organization allows tremendous economy in the amount of information that natural selection needs to encode in the genome. In this way, the study of self-organization in biological systems promotes orthodox evolutionary explanation, not heresy.

Consequently, evolutionary economists who propose that self-organization theory is an alternative to Darwinian principles are at variance with their prominent mentors in selforganization theory. Leading theorists of self-organization recognize that natural selection is required at some point in the explanation. Otherwise there is a gaping hole in the argument. Those that emphasize self-organization to the exclusion of selection do not explain how (selforganized) systems are adapted to their environment.

An exclusive focus on self-organization concentrates on the development of the entity, with a relative neglect of its interactions with its environment and no adequate explanation of how the entity comes to be adapted to survive in this environment. The predominant concern is with internal development and evolution from within, even to the extent of defining evolution in these narrow and unwarranted terms. ${ }^{12}$

On the contrary, in biology, neither individuals, species, nor ecosystems are entirely 'selftransforming'. Evolution takes place within open systems involving both endogenous and exogenously stimulated change. Generally, evolution takes place both through internal changes and interactions with the (possibly changing) environment. Often the environment changes because of migrations and intrusions from another region. As already observed by Darwin (1859), isolation mechanisms have important effects on the evolutionary path of ecosystems. Isolation gives new variation time to evolve slowly, but generally reduces the level of new variation that is being produced. The breakdown of isolation mechanisms increases the level of variation present in a population, sometimes leading to the overcoming of system rigidities.

In biology, much change in a given area is due to introductions of existing species from other regions, which interact with their new neighbors and affect the course of evolution. Exogenous shocks, such as meteor impacts and climate change, are also believed to have had

12 Witt (2003, p. 13) has repeatedly defined evolution as 'the self-transformation over time of a system'. This is redolent of epigenesis and echoes similar and equally confined conceptions of evolution as primarily one of a system changing 'from within' by Marx, Schumpeter and others. On the other hand, Witt's emphasis on the creation of novelty is entirely consistent with a Darwinian approach, especially when external as well as internal stimuli for creativity are taken into account. 
major influence on the evolutionary process, leading to the extinction of some species and the expansion of others.

Likewise, in social evolution, exogenously stimulated change is sometimes of great importance, partly because of the cultural mechanisms of imitation and conformism that tend to reduce internal variety and can lead to institutional ossification. Exogenous shocks can sometimes overcome the rigidity of the system. Many historical examples illustrate this, such as the seventeenth century revolutions in England being sparked by outside forces from Scotland and elsewhere. The arrival of American warships in Tokyo Bay led to the Meiji Restoration of 1868 and the abrupt transition of Japan from feudalism to a Western-inspired capitalist society. The occupation of Japan and Germany by American and allied troops in 1945 also led to major institutional changes. The course of institutional evolution was altered by the intrusion of new forces across the boundaries of the system, as in many other cases of institutional transformation being promoted by invasion or other forces from outside.

On its own, self-organization theory can adequately explain neither the current adaptedness nor the process of adaptation to the environment. Self-organization theory further leaves unexplained the effects of environmental changes on a population of entities. In biology, selforganization is insufficient to address the contingent nature of life and the basic problem of survival and reproduction. To repeat, self-organization can help to explain how undesigned social orders emerge, but itself it explains neither (a) the characteristics of the agents that interact to create the emergent order, (b) how the emergent order reacts to competing social orders, nor (c) more generally how an emergent order adapts and survives in the broader social and natural environment. It leaves out two necessary processes of selection: that which led to the original population of (interacting) agents, and that which ensured that the emergent order adapted and survived. Indeed, such an explanation is most straightforward if we consider a selection process in a population of competing emergent orders. This implies that the capacity to adapt at the level of an individual emergent order must be explained as the outcome of population-level adaptation among competing emergent orders.

As the leading biologist Theodosius Dobzhansky (1962, p. 16) put it, 'No theory of evolution which leaves the phenomenon of adaptedness an unexplained mystery can be acceptable.' Some theory of adaptation and survival is essential. Lacking such an account, self-organization is highly inadequate as a general, evolutionary theory. In response to the self-organization theorists, Gary Cziko (1995, p. 323) similarly argued,

the laws of physics acting on nonliving entities can lead to spontaneous complexity, but nothing in these laws can guarantee adapted complexity of the type seen in living organisms ... Of all the complex systems and structures that may self-organize due to the forces of nature, there can be no assurance that all or any of them will be of use for the survival and reproduction of living organisms.

In other words, self-organization itself cannot account for the survival potential of a selforganized system. Ideas of self-organization may help us understand the emergence of some pattern and order, but they cannot themselves account for the survival value of the order or system itself, especially when compared with rival entities or organisms.

At this stage, in evaluating the limits of self-organization, it is useful to introduce and distinguish the concepts of ontogeny and phylogeny. In biology, ontogeny refers to the growth and development of single organisms from embryo to adult. In this case, changes in the genetic material or genotype are irrelevant to the explanation. Similarly, self-organization involves an ontogenetic evolutionary process, in that it addresses the development of a particular organism or structure, not the constituent elements. 
This does not rule out the possibility that ontogeny can also involve the natural selection of entities within the organism. For example, the growth of many organisms involves the natural selection of immunities, neural patterns and (often beneficial) bacteria in their gut (Edelman 1987, Plotkin 1994, Hull et al. 2001). Likewise, the ontogenetic growth of a firm may involve the internal selection of habits or routines (Nelson and Winter). Hence some descriptions of self-organizing processes involve some (phylogenetic) selection of constituent components of the emerging structure.

However, accounts of self-organization or ontogeny do not necessarily involve selection or phylogeny. Phylogeny refers to the evolutionary history of a group of organisms, such as a species. By definition, phylogeny means the existence and evolution of a whole population within which selection occurs. In a phylogenetic process the genetic material in the whole population changes. Natural selection is always phylogenetic as well as ontogenetic, in that it addresses the evolution of whole populations of organisms or structures as well as the development of individual organisms. In general, ontogeny may but does not necessarily incorporate phylogeny; but phylogeny always incorporates ontogeny. The status of the two concepts is thus unequal, as phylogeny is more general than ontogeny. ${ }^{13}$

From the point of view of the overall evolutionary process, complete evolutionary descriptions require a phylogenetic account of the selection of ontogenetically developing units. Hence while self-organization is important (and perhaps essential), it cannot provide a complete evolutionary description. This must involve phylogeny as well as ontogeny. If we are confined to ontogeny then our description of the overall evolutionary process is incomplete; it does not address the differential survival and fecundity of different (selforganized) structures or organisms. Consequently, self-organization may be an important part of evolution and ontogenetic development, but it cannot replace natural selection.

Self-organization theorists have shown how complex structures can emerge without design, but these structures are themselves subject to evolutionary selection. Some will survive longer and be more influential than others: selection will operate. We have every reason to see these issues as relevant to economic evolution. Conscious choices, competitive pressures, market forces or environmental constraints operate on habits, customs, technologies, institutions, regions and even whole economies. Many of these contain self-organized structures, but this neither precludes nor demotes the role of evolutionary selection.

Furthermore, some processes of self-organization may themselves depend on past selection. An often cited example is the ribosome: when the parts are introduced, the structure snaps into place. But the shapes of the components that fit together are the result of past selection; some parts fail to self-assemble when structure-altering mutations are introduced. Selforganization may depend on both anterior and posterior processes of selection.

\section{Can Darwinism cope with intentionality?}

13 The status of phylogeny versus ontogeny has been the source of much dispute in biology (Baguñà and Garcia-Fernàndez 2003, Gilbert et al. 1996), commonly known as the evo-devo debate. According to a number of developmental biologists, a new synthesis of evolutionary biology and developmental biology (evo-devo synthesis) is called for because, in their own words, 'macroevolutionary questions, are not seen as being soluble by population genetics, and the developmental actions of genes involved with growth and cell specification are seen as being critical for the formation of higher taxa' (Gilbert et al. p. 357). Such proponents view ontogeny as more important than phylogeny. Nevertheless, even if phylogeny it is less important, development requires both phylogeny and ontogeny (Stadler et al. 2001). 
A widespread accusation against the Darwinian account of evolution is that it is 'blind'. More specifically, some authors interpret the alleged 'blindness' of Darwinian evolution to mean that it assumes that organisms, including humans, act as if they are fumbling in the dark with little conception of what they are doing or where they are going.

Darwin did not treat humans as if they were incapable of self-reflection, reason, foresight, purpose or planning. Such attributes are neither irrelevant nor entirely absent in the nonhuman animal world. As Darwin (1859, p. 208) wrote: 'A little dose ... of judgment or reason often comes into play, even in animals very low in the scale of nature.' As Darwin (1871, vol. 1, p. 46) repeated elsewhere: 'animals possess some power of reasoning. Animals may constantly be seen to pause, deliberate and resolve.' As he believed that animals had powers of reasoning, then he would hardly have belittled or denied them for humans.

Nevertheless there are other senses in which evolution may be blind. One sense in which Darwinian evolution is blind is the same as the sense in which self-organization is blind, that particular outcomes are not necessarily prefigured or predicted in advance: design emerges without a seeing designer (Vanberg 2004). This should not be taken to mean that individual agents or organisms within the system are necessarily unable to prefigure or plan their own actions. Another sense in which Darwinian evolution is blind, even in the human domain, is stressed by Donald T. Campbell (1987) who argues that any effective capacity for foresight or prescience must be based on tried and tested knowledge, otherwise we have no grounds to presume its effectiveness. Accordingly when genuine innovations are launched, we are unable to assess the probability of their success or failure. In this sense, all genuine novelties and innovations are blind. Again this does not undermine the reality or importance of human deliberation, intention, foresight or creativity.

In a related objection to the application of Darwinian principles to social evolution, the economist John R. Commons (1924, 1934) repeatedly proposed that institutional evolution involves 'artificial' rather than 'natural' selection. As Commons acknowledged, Darwin himself established the idea of artificial selection, which occurs when a human breeder selects strains of a plant or animal according to favored attributes for further propagation.

The essential characteristic of artificial selection is that humans manipulate the criteria or environment of selection; the selection process is under the control of a human agent. However, it would be a misunderstanding to see artificial selection as an alternative to natural selection. Darwin did not propose that 'artificial' and 'natural' selection are mutually exclusive. On the contrary, he used artificial selection as an exemplar for natural selection. Furthermore, at a high level of abstraction, artificial and natural selection share an identical definition (Hull 1988, Price 1995, Knudsen 2004).

Crucially, the human doing the selection is also a product of natural evolution. The dispositions, aims and criteria that humans use in selecting specimens for 'artificial' selection are also the products of processes of cognitive and cultural evolution. The phenomenon of humans selecting between outcomes or possibilities is important and real, but their preferences and choices have also, as far as possible, to be explained.

When 'artificial selection' does take place, it is not the end of the story. Different institutions or societies in which artificial selection is involved sometimes compete against each other. Hence some additional processes of evolutionary selection may be involved. Sometimes despite human intentions, some institutions will survive while others may not. Natural events or other forces may influence the selection outcome. Any outcome of 'artificial' selection has to be tested in the environment. Artificial selection cannot replace or demote a broader concept of evolutionary selection in human society. 
The compartmentalization of artificial from natural selection sometimes relies on a notion of intention as something distinct and separate from the multiple causal linkages of nature. Intentions are real and have effects. Nevertheless, intentions themselves are caused. According to Darwin's ontological outlook, everything must submit to a causal explanation in scientific terms. Darwinism does not exclude deliberative and calculative behavior. On the contrary, Darwin insisted that calculations and intentions had to be explained.

Intentionality would have little bite unless it was guided by prior knowledge and experience, which in turn is necessarily shaped by the individual's habits and instincts. Thus, in order to explain why decision-makers intend particular outcomes, why they sometimes continue to intend particular outcomes despite negative feedback, and why systematic errors often continue to lead to unintended and unwanted outcomes, it is important to understand how intentions build upon prior habits and instincts.

In the social sciences, it is often still taken for granted that the existence of a human intentionality is sufficient to explain human action, without probing the causes behind intentions themselves. Darwinism does not deny belief, choice, purposeful behavior or foresight: it simply asserts that they too are caused and worthy of explanation. Indeed, Darwinism has an important role in explaining how agents formulate and revise goals, how agents generate new alternatives and why goal-directed behavior very often leads to failure. ${ }^{14}$

\section{The Lamarckian confusion}

Many social scientists have described social evolution as 'Lamarckian'. Typically this notion is not defined carefully, and it is often counter-posed to Darwinism. Sometimes it is associated with the idea that evolution is driven by will or purpose. However, Jean-Baptiste de Lamarck (like Darwin) was a philosophical materialist and saw intention or volition as rooted in material causes (Boesiger 1974). Instead it was later 'Lamarckians' that made unexplained will or purpose so central to a depiction of evolutionary change. ${ }^{15}$

Still Lamarck and the Lamarckians had something important in common: they all believed in the inheritance of acquired characters. Darwin (1859, pp. 82, 137, 209) never denied a limited role for the inheritance of acquired characters, and in his later life he gave it increasing rather than decreasing attention and approval. Hence Lamarckism (in this sense) and Darwin's doctrine are not necessarily mutually exclusive. We now know that the possibility of the inheritance of acquired characters is non-existent or highly limited at the level of genetic evolution. ${ }^{16}$ In contrast, it has been argued by many that acquired characters can be passed on and inherited in the social domain.

14 This point has recently been acknowledged by some economists who have begun to explore the Darwinian basis of tastes and preferences relevant for labor markets and consumption choices (Rubin and Somanathan 1998).

15 The idea that Lamarck's theory necessarily involves organisms willing their own adaptations probably emanates from an 1830 caricature of Lamarck’s views by G. Cuvier (Richards 1987, p. 63). It does not derive from Lamarck himself (Burkhardt 1984, pp. xxx-xxxi).

16 There is a minority view among biologists that the inheritance of acquired characters may be possible in a restricted set of circumstances, such as the transfer of acquired immunities from mother to child (Steele 1979, Ho 
Three working definitions of Darwinism, Lamarckism and Weismannism ${ }^{17}$ (or neoDarwinism) are suggested below:

- Darwinism is a causal theory of evolution in complex population systems involving the inheritance of generative instructions by individual units and a process of selection of the varied population of such entities.

- $\quad$ Lamarckism is a doctrine admitting the possibility of the (genotypic) inheritance of acquired (phenotypic) characters by individual organisms in evolutionary processes.

- Weismannism (or neo-Darwinism) is a doctrine denying the possibility of the (genotypic) inheritance of acquired (phenotypic) characters by individual organisms in evolutionary processes.

Note first that the first two (Darwinism and Lamarckism) are not mutually exclusive, whereas Lamarckism is the opposite of Weismannism and one denies the other. Not only is the relationship between Lamarckism and Darwinism asymmetrical, but also they involve different degrees of explanatory completeness: there are gaps in the Lamarckian story. In particular, if acquired characters can be inherited, what is to prevent the inheritance of acquired injuries or impairments? If every acquired characteristic were inherited, then every newborn human would be aged and wrinkled like its parents. There must be a mechanism that allows beneficial characters to be inherited, but reduces the probability of inheriting injuries or other acquired impairments. The only plausible mechanism is natural selection itself. Accordingly, Lamarckism depends on the Darwinian principle of selection in order to explain why any disastrous propensity to inherit acquired impairments does not prevail. As Richard Dawkins (1986, p. 300) argues, 'the Lamarckian theory can explain adaptive improvement in evolution only by, as it were, riding on the back of the Darwinian theory.' Consequently Lamarckism, if valid in any particular domain, depends on Darwinian mechanisms of selection for evolutionary guidance. By contrast, Darwinism has a broader applicability and remains valid in spheres where Lamarckian inheritance does not occur. Even if it is valid, then Lamarckism requires Darwinism as an explanatory crutch.

Insofar as organisms are purposeful, this capacity too has evolved through natural selection. Darwinism thus points to an evolutionary explanation of the very origin of will of purpose itself. Hence overall, Darwinism is a more general and powerful theory than Lamarckism. If social evolution can be legitimately described as Lamarckian in the sense of admitting the possibility of inheritance of acquired characters, then this Lamarckism must be nested within a Darwinian theory.

Accordingly, Lamarckism is not an alternative to Darwinism, even in the social sphere. It is erroneous to see them as rivals because Lamarckism depends on Darwinian natural selection to complete its explanations. Hence Witt (1999, p. 288) and many others are wrong to presume that social learning and social evolution are 'more akin to Lamarckian than to Darwinian evolution.' There is nothing in social evolution that contradicts the core Darwinian principles, and these general principles do not themselves exclude the possibility of acquired character inheritance. Even if we can talk of acquired characters being inherited in the social

and Saunders 1984, Jablonka et al. 1992, Steele et al. 1998). We entirely abstain from evaluating these minority arguments in biology, and our arguments are unaffected by either their validity or their falsehood.

17 Named after the German Darwinian biologist August Weismann (1893) who proposed strong empirical and theoretical arguments against the possibility of acquired character inheritance in the biological domain. 
domain, then this does not undermine the greater explanatory importance of Darwin's theory. ${ }^{18}$

\section{Why Darwinism is not enough}

It is argued above that complex population systems are found in both nature and the human social world. Furthermore, their evolution involves some shared Darwinian principles. It is not that social evolution is analogous to evolution in the natural world; it is that at a high level of abstraction, social and biological evolution share these general principles. In this sense, social evolution is Darwinian.

This proposition might provoke the accusation that it ignores the big differences between the mechanisms of social and biological evolution. Of course, they are hugely dissimilar in all sorts of details. Nothing corresponds closely in the social domain to DNA, sexual recombination and much else. Social units such as routines and institutions can change much more rapidly than human DNA, and they replicate by very different mechanisms. But Darwinism is more general and is not tied to these particulars. Indeed, not all biological replication is sexual, biparental or via DNA. Furthermore, not all biological evolution is slow: some bacteria evolve quickly, and very rapid biological replication and mutation can occur with viruses. ${ }^{19}$

Accordingly, Witt (2004, p. 128) is mistaken in his characterization that a universal or generalized Darwinism 'supposes that there is only one and the same ontological basis for all evolutionary phenomena'. While the biological and the social are different levels of the same world, the detailed ontology of (say) genes is different from the detailed ontology of (say) the immune system, and both are very different from the detailed ontology of the human social world. A generalized Darwinism proposes that despite these real and severe ontological differences at the level of detail, there are also nevertheless common ontological features at an abstract level. Precisely because it abstracts from the detailed ontological differences, a generalized Darwinism cannot explain everything.

To say that two sets of phenomena are similar in general terms does not imply that they are similar in detailed respects. Mice and elephants are both mammals, but they differ greatly in size, behavior and lifespan. Steam engines and internal combustion engines are very different in mechanics and performance, but they are both carbon fuelled heat engines subject to the laws of thermodynamics. Pebbles and planets are also highly dissimilar, but their trajectories through space can both be calculated adequately by means of Newton's laws of motion.

Not only do natural and social evolution differ greatly in their details, but also detailed mechanisms differ greatly within the biological world. Biological organisms differ enormously in size, lifespan and reproductive fertility. Some species are social, others not. Haploid and diploid organisms have single and paired chromosomes respectively, and their mechanisms of reproduction differ in many ways. An even more fundamental difference is between prokaryotes (no cell nucleus) and eukaryotes (nucleated). The reproduction and

\footnotetext{
18 Furthermore, as elaborated elsewhere, there are general problems in the use of the 'Lamarckian' description in the social domain (Hull 1982, 1988, Hodgson and Knudsen, 2005).

19 Gould (2002) has long argued that the rate of evolution of given lineages is far from uniform, being 'punctuated' by bursts of relatively rapid evolutionary change.
} 
selection of immunities and neural patterns involve very different processes, and these in turn are different from replication and selection of DNA, but all of these are subject to Darwinian principles (Edelman 1987, Darden and Cain 1989, Plotkin 1994, Hull et al. 2001). As well as through seeds, some plants can reproduce by lateral root-sprouts or suckers, cloning a similar and independent plant with identical DNA. Generally, replication among invertebrates is very different from that among vertebrates. And so on.

The differences of mechanism within the biological world are as impressive in some ways as the differences between the biological and the social. Accordingly, the generalization of the Darwinian principles within biology yields propositions of significance far beyond biology itself, encompassing the very different and itself intrinsically diverse world of social evolution. As David Hull (1988, p. 403) puts it, 'the amount of increased generality needed to accommodate the full range of biological phenomena turns out to be extensive enough to include social and conceptual evolution as well.'

The ongoing attempts of evolutionary biologists to understand the variety within the natural world offer lessons for the evolutionary social scientist. It is not to copy slavishly all ideas from the biological to the social domain. It is instead to appreciate the evolving panorama of evolutionary theory in its attempts to explore and understand this complexity, while retaining Darwin's three general principles at the core. The issues are far from settled in evolutionary biology (Stadler et al. 2001), but most agree about the centrality of the Darwinian principles of variation, inheritance and selection.

Given that Darwinism operates at a relatively high degree of generality, it cannot itself give an account of all the details, in either the social or the biological sphere. Darwinism does not provide a complete theory of everything, from cells to human society. Darwinism provides an over-arching framework of explanation, but without claiming to explain every aspect or detail. In insisting that evolution was always dependent on its specific context, Darwin (1859, p. 314) declared: 'I believe in no fixed law of development.'

Crucially, explanations additional to natural selection are always required to explain any evolved phenomenon. For example, natural selection alone cannot explain why some birds have dull, and others colorful, plumage. Different auxiliary explanations are required, such as camouflage against predators in some cases, or competition for mates and sexual selection in others. Selection is the general principle, but it operates in different ways. Even in biology there is an important difference between predator selection and sexual selection. Natural selection does not itself induce variability at the individual level, and additional theories are required to explain this. The sources of variation are very different in different contexts. The general Darwinian principle of variation applies, but it does not itself explain how variation occurs.

Accordingly, the transfer of Darwinian principles from biological to social evolution does not imply that the detailed mechanisms of selection, variation and inheritance are similar. On the contrary, the important differences between and within the two spheres suggest that the details are very different, and there are bound to be many detailed mechanisms in the social world that are not found in biology. Consequently, the application of general Darwinian principles cannot do all the explanatory work for the social scientist. Darwinism alone is not enough.

Therefore Witt (2004, p. 141) is right to insist that 'the mechanisms and regularities of cultural evolution differ fundamentally from those of natural evolution. Darwinian theory is therefore not sufficient to explain them.' But the insufficiency of a theoretical approach does not itself deny its necessity. Darwinism is insufficient, but we have argued above that it is also 
necessary at an abstract and highly general level. The very generality of Darwinism hints at a multiple-level mode of theorizing in complex population systems (Hodgson 2001). ${ }^{20}$

The Darwinian framework has a high degree of generality, and it always requires specific auxiliary explanations. The meta-theoretical framework of Darwinism provides a way of inspiring, framing and organizing these explanations (Darden and Cain 1989, Blute 1997, Hodgson 2001). To repeat, this commitment to a general Darwinian framework does not overlook the important differences between the specific mechanisms of evolution in biology and in society. On the contrary, Darwinism always requires further explanations of the particular mechanisms that occur in specific cases. In any relevant domain, Darwinian theory points to a combination of over-arching general principles and much more specific and detailed explanations as a means of understanding evolution in complex systems. Indeed, it is the only general framework that has been devised to deal with the complex population systems that have been described above. But, to repeat, it is never sufficient on its own.

\section{Summary and conclusion}

In generalizing Darwinism to social evolution, we are addressing populations of social entities such as customs, rules, routines, and institutions. The notion of self-organization may be very important in helping to explain in some cases how individual entities develop, but we still require a Darwinian theory to begin to explain the evolution of the whole population of such entities. Self-organization alone cannot explain the adaptation and differential survival of selforganized outcomes.

Human intentionality is very important in the social sphere. Humans have unique capacities for prefiguration and deliberation. Human social interaction also involves the imputation of such powers to others with whom we interact. There is nothing in Darwinism that excludes or belittles human intentionality, prefiguration, deliberation, and choice. What Darwinism requires is that they too should be subject to causal explanation.

Concerning the Lamarckian inheritance of acquired characteristics, most biologists reject such a possibility in the biological domain, and the Lamarckian description is itself problematic. Even if acquired character inheritance did occur on another planet or in social evolution, it would not rule out Darwinism, which is necessary to explain why acquired impairments or injuries are not inherited. Darwinism and Lamarckism are neither rivals nor opposites. If Lamarckian inheritance did occur, then Darwinian principles would be required to complete its explanations. Hence the case for the use of the 'Darwinian' label is much stronger than the 'Lamarckian' one, even in the social context.

In sum, as long as we are addressing a population of replicating entities, then social evolution must be Darwinian, whether or not self-organization, human intentionality, or Lamarckian inheritance are involved. As long as there is a population of replicating entities with varying capacities to survive, then Darwinian evolution will occur.

20 As noted above, Witt (1997, p. 489) upholds that the 'theory of self-organization ... provides an abstract, general description of evolutionary processes.' We argue that it is not sufficiently general to deal with the features of adaptation and selection. But leaving that on one side, Witt's proclamation of such a 'general description' is vulnerable to his own objection (to a generalized Darwinism) that such generalities ignore the vital differences between self-organization in the natural and the social world. He (wrongly) regards this objection to be crucial against a generalized Darwinism, but fails to deploy it against his favored general theory of self-organization. 
Social evolution deals with populations of entities, including customs and social institutions, that compete for scarce resources. Accordingly, we believe that social evolution is Darwinian. This is not essentially a matter of analogy; it is a partial description and analysis of reality. Social evolution is Darwinian by virtue of (social) ontology, not (biological) analogy.

However, the ontological case for extending Darwinism to social evolution refers to very broad ontological communalities, not to matters of detail. To repeat: biological evolution and social evolution are very different with regard to details. Nevertheless, Darwinian modes of explanation are necessary to address the ontologies of evolving populations, in both the biological and the social domains.

However, the notion of a generalized Darwinism itself provides no alternative to a detailed explanation of the particular emergent properties and processes at the social or biological levels. Darwinism does not itself provide all the necessary causal mechanisms and explanations for the social scientist, nor obviate the elaborate additional work of specific investigation and detailed causal explanation in the social sphere (Hodgson 2001).

Darwinism is unavoidable but this does not mean that the core Darwinian theory is sufficient to explain the processes of social evolution. Darwinian principles provide a general explanatory framework into which particular explanations and empirical details have to be placed (Hull 1973). A generalized Darwinism cannot itself give us a full, detailed explanation of evolutionary processes or outcomes. It is more a meta-theoretical framework than a complete theory. For the evolutionary social sciences, as elsewhere, Darwinian general principles are necessary but not sufficient. 


\section{References}

Baguñà, J., Garcia-Fernàndez, J., 2003. Evo-devo: the long and winding road. International Journal of Developmental Biology 47, 705-13.

Bagehot, W., 1872. Physics and Politics, or, Thoughts on the Application of the Principles of 'Natural Selection’ and 'Inheritance' to Political Society. London: Henry King.

Blute, M., 1997. History versus science: the evolutionary solution. Canadian Journal of Sociology 22, 345-364.

Boesiger, E., 1974. Evolutionary theories after Lamarck and Darwin. In: Ayala, F. J., Dobzhansky, T. (Eds.), 1974. Studies in the Philosophy of Biology. London, Berkeley and Los Angeles: Macmillan and University of California Press, 21-44.

Burkhardt, R. W., Jr., 1984. The ‘Zoological Philosophy’ of J. B. Lamarck. In: Lamarck, J. B. de, 1984. Zoological Philosophy: An Exposition with Regard to the Natural History of Animals, translated from the 1st French edn. of 1809 with introductory essays by Hull, D. L., Burkhardt. R. W. Chicago: University of Chicago Press, Xv-xxxix.

Camazine, S., Deneubourg, J.-L., Franks, N. R., Sneyd, J., Theraulaz, G., Bonabeau, E., 2001. Self-Organization in Biological Systems. Princeton: Princeton University Press.

Campbell, D. T., 1987. Blind variation and selective retention as in other knowledge processes. In: Radnitzky, G., Bartley III, W. W. (Eds.), 1987. Evolutionary Epistemology, Theory of Rationality, and the Sociology of Knowledge. La Salle: Open Court, 91-114.

Commons, J. R., 1924. Legal Foundations of Capitalism. New York: Macmillan.

Commons, J. R., 1934. Institutional Economics - Its Place in Political Economy. New York: Macmillan.

Cziko, G., 1995. Without Miracles: Universal Selection Theory and the Second Darwinian Revolution. Cambridge, MA: MIT Press.

Darden, L., Cain, J. A., 1989. Selection type theories, Philosophy of Science 56, 106-129.

Darwin, C. R., 1859. On the Origin of Species by Means of Natural Selection, or the Preservation of Favoured Races in the Struggle for Life. London: Murray.

Darwin, C. R., 1871. The Descent of Man, and Selection in Relation to Sex. 2 vols. London and New York: Murray and Hill.

Dawkins, R., 1976. The Selfish Gene. Oxford: Oxford University Press.

Dawkins, R., 1983. Universal Darwinism. In: D. S. Bendall (Ed.), 1983. Evolution from Molecules to Man. Cambridge: Cambridge University Press, 403-425.

Dawkins, R., 1986. The Blind Watchmaker. Harlow: Longman.

Depew, D. J., Weber, B. H., 1995. Darwinism Evolving: Systems Dynamics and the Genealogy of Natural Selection. Cambridge, MA: MIT Press.

Dobzhansky, T., 1962. Mankind Evolving: the Evolution of the Human Species. New Haven: Yale University Press.

Edelman, G. M., 1987. Neural Darwinism: The Theory of Neuronal Group Selection. New York: Basic Books. 
Eigen, M., Schuster, P., 1979. The Hypercycle: A Principle of Natural Self-Organization. New York: Springer-Verlag.

Foster, J., 1997. The analytical foundations of evolutionary economics: from biological analogy to economic self-organisation. Structural Change and Economic Dynamics 8, 427451.

Gilbert, S. F., Opitz, J. M., Raff, R. A., 1996. Resynthesizing evolutionary and developmental biology. Developmental Biology 173, 357-372.

Gould, S. J., 2002. The Structure of Evolutionary Theory. Cambridge, MA: Harvard University Press.

Hayek, F. A., 1973. Law, Legislation and Liberty; vol. 1: Rules and Order. London: Routledge and Kegan Paul.

Hayek, F. A., 1988. The Fatal Conceit: The Errors of Socialism. The collected works of Friedrich August Hayek, Vol. I, Ed. William W. Bartley III. London: Routledge.

Ho, M.-W., Saunders, P. T. (Eds.), 1984. Beyond Neo-Darwinism: An Introduction to the New Evolutionary Paradigm. London: Academic Press.

Hodgson, G. M., 1993. Economics and Evolution: Bringing Life Back into Economics. Cambridge, UK and Ann Arbor, MI: Polity Press and University of Michigan Press.

Hodgson, G. M., 2001. How Economics Forgot History: The Problem of Historical Specificity in Social Science. London and New York: Routledge.

Hodgson, G. M., 2002. Darwinism in economics: from analogy to ontology. Journal of Evolutionary Economics 12, 259-281.

Hodgson, G. M., 2003. The mystery of the routine: the Darwinian destiny of 'An Evolutionary Theory of Economic Change’. Revue économique 54, 355-384.

Hodgson, G. M., 2004. The Evolution of Institutional Economics: Agency, Structure and Darwinism in American Institutionalism. London and New York: Routledge.

Hodgson, G. M., Knudsen, T., 2004. The firm as an interactor: firms as vehicles for habits and routines. Journal of Evolutionary Economics 14, 281-307.

Hodgson, G. M., Knudsen, T., 2005. Dismantling Lamarckism: Why descriptions of socioeconomic evolution as Lamarckian are misconceived. Unpublished.

Hofbauer, J., Sigmund, K., 1998. Evolutionary Games and Population Dynamics. Cambridge: Cambridge University Press.

Hull, D. L., 1973. Darwin and His Critics: The Reception of Darwin's Theory of Evolution by the Scientific Community. Cambridge, MA: Harvard University Press.

Hull, D. L., 1982. The naked meme. In: H. C. Plotkin (Ed.), 1982. Learning, development and culture: essays in evolutionary epistemology. New York: Wiley, 273-327.

Hull, D. L., 1985. Darwinism as a historical entity: a historiographic proposal. In: Kohn, D. (Ed.), The Darwinian Heritage. Princeton: Princeton University Press, 773-812.

Hull, D. L., 1988. Science as a Process: an Evolutionary Account of the Social and Conceptual Development of Science. Chicago: University of Chicago Press.

Hull, D. L., 2001. In search of epistemological warrant. In: Heyes, C. C. and Hull, D. L. (Eds.), 2001. Selection Theory and Social Construction: The Evolutionary Naturalistic 
Epistemology of Donald T. Campbell. Albany: State University of New York Press, 155168.

Hull, D. L., Langman, R. E., Glenn, S. S., 2001. A general account of selection: biology, immunology and behavior. Behavioral and Brain Sciences 24, 511-573.

Jablonka, E., Lachmann, M., Lamb, M. J., 1992. Evidence, mechanisms and models for the inheritance of acquired characters. Journal of Theoretical Biology 158, 245-268.

Kauffman, S. A., 1993. The Origins of Order: Self-Organization and Selection in Evolution. Oxford and New York: Oxford University Press.

Kauffman, S. A., 1995. At Home in the Universe: The Search for Laws of Self-Organization and Complexity. Oxford and New York: Oxford University Press.

Kauffman, S. A., 2000. Investigations. Oxford and New York: Oxford University Press.

Keller, A. G., 1915. Societal Evolution: A Study of the Evolutionary Basis of the Science of Society. New York: Macmillan.

Keller, E. F., 2002. Making Sense of Life: Explaining Biological Development with Models, Metaphors, and Machines. Cambridge, MA: Harvard University Press.

Knudsen, T., 2002. Economic selection theory. Journal of Evolutionary Economics 12, 443470.

Knudsen, T., 2004. General selection theory and economic evolution: The Price equation and the replicator/interactor distinction. Journal of Economic Methodology 11, 147-173.

Mayr, E., 1991. One Long Argument: Charles Darwin and the Genesis of Modern Evolutionary Thought. Harvard University Press and Allen Lane: Cambridge, MA and London.

Metcalfe, J. S., 1998. Evolutionary Economics and Creative Destruction. London and New York: Routledge.

Nelson, R. R., 1991. Why do firms differ, and how does it matter? Strategic Management Journal 12, 61-74.

Nelson, R. R., Winter, S. G., 1982. An Evolutionary Theory of Economic Change. Cambridge, MA: Harvard University Press.

Neumann, J. von., 1966. Theory of Self-Reproducing Automata. Ed. and completed by A. W. Burks. Urbana: University of Illinois Press.

Plotkin, H. C., 1994. Darwin Machines and the Nature of Knowledge: Concerning Adaptations, Instinct and the Evolution of Intelligence. Harmondsworth: Penguin.

Price, G. R., 1995. The nature of selection. Journal of Theoretical Biology 175, 389-396.

Richards, R. J., 1987. Darwin and the Emergence of Evolutionary Theories of Mind and Behavior. Chicago: University of Chicago Press.

Richards, R. J., 1992. The Meaning of Evolution: the Morphological Construction and Ideological Reconstruction of Darwin's Theory. Chicago: University of Chicago Press.

Ritchie, D. G. 1896. Social evolution. International Journal of Ethics 6, 165-181.

Robbins, L., 1932. An Essay on the Nature and Significance of Economic Science. London: Macmillan. 
Rubin, P. H., Somanathan, E., 1998. Humans as factors of production: an evolutionary analysis. Managerial and Decision Economics 19, 441-455.

Saviotti, P. P., 1996. Technological Evolution, Variety and the Economy. Aldershot: Edward Elgar.

Stadler, B. M. R., Stadler, P. F., Wagner, G. P., 2001. The topology of the possible: formal spaces underlying patterns of evolutionary change. Journal of Theoretical Biology 213, 241-274.

Steele, E. J., 1979. Somatic Selection and Adaptive Evolution: On the Inheritance of Acquired Characters. Toronto: Williams-Wallace International.

Steele, E. J., Lindley, R. A., Blanden, R. V. and Davies, P.1998. Lamarck’s Signature: how Retrogenes are Changing Darwin's Natural Selection Paradigm. New York: Perseus.

Vanberg, V. J., 2004. Human intentionality and design in cultural evolution. Paper prepared for the workshop on the Evolution of Designed Institutions, Max Planck Institute for Research into Economic Systems, Jena, February, 19-21, 2004.

Veblen, T. B. 1899. The Theory of the Leisure Class: an Economic Study in the Evolution of Institutions. New York: Macmillan.

Veblen, T. B., 1919. The Place of Science in Modern Civilization and Other Essays. New York: Huebsch.

Weber, B. H., Depew, D. J., 1996. Natural selection and self-organisation: dynamical models as clues to a new evolutionary synthesis. Biology and Philosophy 11, 33-65.

Weismann, A. 1893. The Germ-Plasm: A Theory of Heredity. London and New York: Walter Scott and Scribner's.

Wicken, J. S., 1987. Evolution, Thermodynamics, and Information: Extending the Darwinian Paradigm. Oxford and New York: Oxford University Press.

Winter, S. G., Jr., 1971. Satisficing, Selection and the Innovating Remnant. Quarterly Journal of Economics 85, 237-61.

Witt, U., 1997. Self-organisation and economics - what is new? Structural Change and Economic Dynamics 8, 489-507.

Witt, U., 1999. Evolutionary economics and evolutionary biology. In: Koslowski, P. (Ed.), 1999. Sociobiology and Bioeconomics: The Theory of Evolution in Biological and Economic Theory. Berlin: Springer, 279-298.

Witt, U., 2003. The Evolving Economy: Essays on the Evolutionary Approach to Economics. Cheltenham UK and Northampton MA: Edward Elgar.

Witt, U., 2004. On the proper interpretations of 'evolution' in economics and its implications for production theory. Journal of Economic Methodology 11, 125-146. 